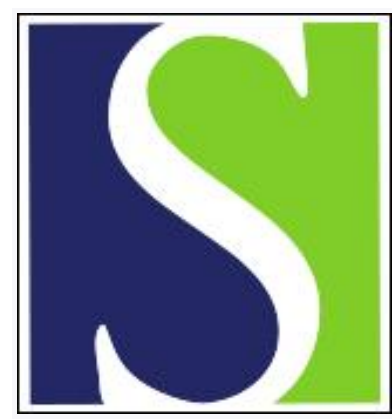

Scand J Work Environ Health 2006;32(2):109-210

https://doi.org/10.5271/sjweh.986

Issue date: 30 Apr 2006

Salivary cortisol and self-reported stress among persons with environmental annoyance

by Carlsson F, Persson R, Karlson B, Österberg K, Hansen ÅM, Garde AH, Ørbæk P

Affiliation: Division of Occupational and Environmental Medicine, Barngatan 2, Lund University Hospital, 22185 Lund, Sweden. frida.carlsson@med.lu.se

Refers to the following text of the Journal: 2004;30(6):486-496

The following article refers to this text: SJWEH Supplements 2006;(2):15-21

Key terms: environmental annoyance; environmental illness; salivary cortisol; self-assessment; self-report; self-reported stress

This article in PubMed: www.ncbi.nlm.nih.gov/pubmed/16680381

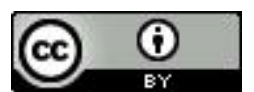




\title{
Salivary cortisol and self-reported stress among persons with environmental annoyance
}

\author{
by Frida Carlsson, PhD, ${ }^{1}$ Roger Persson, PhD, ${ }^{1,2}$ Björn Karlson, PhD, ${ }^{1}$ Kai Österberg, PhD, ${ }^{1}$ Åse Marie \\ Hansen, PhD, ${ }^{2}$ Anne Helene Garde, PhD, ${ }^{2}$ Palle Ørbæk, MD ${ }^{2}$
}

\begin{abstract}
Carlsson F, Persson R, Karlson B, Österberg K, Hansen ÅM, Garde AH, Ørbæk P. Salivary cortisol and selfreported stress among persons with environmental annoyance. Scand J Work Environ Health 2006;32(2):109120.
\end{abstract}

Objectives Increased vulnerability to stress has been suggested as a possible mechanism behind medically unexplained conditions such as sensitivity to electricity and common smells. This study examined whether subjective environmental annoyance among the general population is associated with increased physiological reactivity or subjective stress scores.

Methods Four groups were studied ( $\mathrm{N}=141)$ : an electrically annoyed $(\mathrm{N}=17)$, a smell-annoyed $(\mathrm{N}=29)$, and a generally annoyed group $(\mathrm{N}=39)$ and a reference group matched for age, gender, and socioeconomic status $(\mathrm{N}=56)$. Over 5 days, the participants collected saliva for cortisol determination at awakening, 30 minutes after awakening, 8 hours after awakening, and at 9 o'clock in the evening. On the evening preceding the fifth day, the participants ingested a 0.5 -mg dexamethasone tablet so that possible differential suppression of the hypothalamic-pituitary-adrenal (HPA) axis could be assessed. Each day, the participants also rated their subjective stress and health complaints.

Results No significant differences were found between the groups regarding cortisol secretion over 5 days. The dexamethasone suppression test showed inhibited cortisol secretion in all four groups. No associations were found between the cortisol concentrations and the self-reported stress scores or subjective health complaints.

Conclusions Although the environmentally annoyed groups showed no signs of increased HPA-axis activation, being annoyed by both electrical devices and smells seems to be related to increased psychological activation in terms of self-reported stress. Because the participants were otherwise healthy and recruited from the general population, the results imply that subtle psychological stress processes may be important in the early development of environmental annoyance.

Key terms environmental illness.

Annoyance related to electrical and chemical factors has been shown to be fairly common in the general population (1). In some cases, such nonallergic annoyance may develop into states of severe intolerance, such as idiopathic environmental intolerance. It is poorly understood why some persons develop strong reactions to common environmental factors, tolerated by most people, and no general agreement on any specific mechanism behind idiopathic environmental intolerance exists (2). However, most current models suggest that environmental intolerance is acquired through psychobiological learning processes in the central nervous system. One suggested mechanism is sensitization, that is, an increased respon- sivity to a stimulus induced by repeated exposure (3). Other mechanisms are classical and operant conditioning and modeling (4). High arousal has been shown to facilitate both sensitization and classical conditioning (5); this finding suggests that persons with a higher reactivity to stress (ie, reacting with arousal quicker or more strongly when faced with a stressor) may be more prone to learn to associate annoyance with environmental factors. The stress response also affects the endocrine system, the vegetative nervous system, the immune system, and the biochemistry of the brain, inducing increased vigilance (6), which may facilitate the development of a cognitive bias towards somatic sensations

1 Division of Occupational and Environmental Medicine, Department of Laboratory Medicine, Lund University, Lund, Sweden.

2 National Institute of Occupational Health, Copenhagen, Denmark.

Reprint requests to: Frida Carlsson, Division of Occupational and Environmental Medicine, Barngatan 2, Lund University Hospital, 22185 Lund, Sweden. [E-mail: frida.carlsson@med.lu.se] 
in relation to environmental triggers, in order to be able to predict and avoid situations facing the trigger (7). From the perspective of the cognitive activation theory of stress (CATS), the core feature of this sensitized stage is a firmly established negative outcome expectancy in presumed trigger situations, which, through sustained arousal, perpetuates annoyance reactions and may lead to an interpretation of the stress response in terms of chronic illness (5).

The stress response, or "alarm reaction", affects the activity in the hypothalamic-pituitary-adrenal (HPA) axis, leading to an elevated secretion of cortisol. The release of cortisol normally follows a robust circadian rhythm, with peaking levels in the morning following awakening and then declining levels thereafter throughout the day. The morning increase is typically reported to be about $50-100 \%$, peaking about 30 minutes after awakening (8-11). This circadian rhythm is believed to be fairly stable over time in the same person $(8,10,11)$, and, when measured repeatedly and with reference to awakening, as opposed to being measured in a single assessment at a fixed time, the awakening response is considered a reliable biological measure of adrenocortical activity $(9,11)$.

The diurnal pattern has been shown to be affected in different psychiatric and somatic conditions, which have been associated with stress either directly or indirectly (12-18). In some conditions, hyperactivity of the HPA axis has been observed, with generally higher cortisol levels and blunted negative feedback after low-dose dexamethasone intake. Increased HPA activity has been found in acute stress situations, both in the laboratory and in real life, such as bereavement, increased work demands, somatization, and major depression (12-14, $17,18)$. By contrast, some conditions have been associated with lowered cortisol levels, flattened diurnal curves, and enhanced suppression of cortisol after dexamethasone (ie, hypocortisolism) (13). Conditions associated with hypocortisolism include chronic stress, vital exhaustion, posttraumatic stress disorder, rheumatoid arthritis, fibromyalgia, and chronic fatigue syndrome $(13,15,16)$. With regard to the chronic fatigue syndrome, some studies have failed to find this association, reporting normal cortisol levels but enhanced suppression $(19,20)$. Cortisol secretion during everyday life has not previously been studied in persons with environmental annoyance.

The overall aim of this study was to examine whether subjective environmental annoyance is associated with increased physiological or subjective stress reactivity. Because population samples, in contrast to patient samples, are likely to be less affected by care seeking, or sick-role behavior, a procedure including a sample drawn from the general population was adopted, as it was expected to allow us to study the phenomenon at a preclinical level. Specifically, the purpose of this study was threefold. To begin with, it was of interest to describe and chart the HPA-axis activity in three environmentally annoyed groups. The second aim was to examine to what degree environmentally annoyed persons had over-reactivity in the HPA-axis, as measured by diurnal salivary cortisol sampling and a dexamethasone suppression test. It was hypothesized that the three environmentally annoyed groups, in comparison with referents, would have higher mean cortisol levels and a higher cortisol awakening response and would show reduced suppression of the HPA response after overnight dexamethasone intake. The third aim was to examine whether the measures of psychophysiological activity were associated with self-reported psychological stress or subjective health complaints.

\section{Study population and methods}

\section{Study population}

The participants were recruited from a large group of respondents $(\mathrm{N}=13$ 381) to a questionnaire survey distributed by mail to a sample $(\mathrm{N}=23437)$ representative of the population in Skåne (Scania), Sweden, born between 1919 and 1981. The fairly good representativity of this survey population has been described earlier by Carlsson et al (21). The survey contained five questions concerning subjective annoyance from environmental factors, on which the selection of participants into the present study was based. Three of the questions concerned annoyance related to electrical equipment and the other two questions covered annoyance related to chemicals or smells. The questions were, "During the past 14 days, did you experience annoyance that you associate with: (i) fluorescent tube lighting; (ii) visual display units; (iii) other electrical equipment; (iv) breathing air that smells of chemicals; and (v) other smells; and, if so, how much annoyance did this cause you?" Each environmental annoyance category could be rated at any of three levels of annoyance: "No", "Yes, some", or "Yes, very much". From all of the persons who, in the first survey, had reported experience of "very much" annoyance in response to at least one of the five environmental factors, we selected those who were $<55$ years old when responding to the public health survey, and, therefore, $<58$ years of age at the time of the present study. Persons who were on long-term sick leave or were diabetic at the time of the first survey were excluded. This exclusion resulted in 315 persons who were invited to take part in the study on stress and environmental annoyance. Out of these 315, altogether 118 agreed to participate, and 86 actually started to participate in the study. One person dropped out of the study 
during the 2-week period, leaving 85 persons completing the study. The participants were subclassified into the following three subgroups: (i) an electrically annoyed (EA) group $(\mathrm{N}=17)$, who reported the highest level of annoyance in response to at least one of the factors listed in questions 1-3 (ie, concerning electricity), but no annoyance at all from the factors named in questions 4 and 5 (ie, concerning smells); (ii) a smell-annoyed (SA) group ( $\mathrm{N}=29)$, who reported the highest level of annoyance with regard to at least one of questions 4 and 5, but no annoyance at all from any of the factors given in questions $1-3$; and (iii) a generally annoyed (GA) group ( $\mathrm{N}=39$ ), who reported the highest level of annoyance in response to at least one of the factors related to either electricity or smells (questions 1-3 or 45 ), together with at least "some" annoyance from one or more factors within the other category.

Altogether 235 referents matched for age, gender, and socioeconomic status were invited to participate in the study, 79 of whom accepted and 57 of whom participated, 56 completing the study. Some characteristics of the participants are shown in tables 1 and 2; a more detailed description can be found in Österberg et al (22).

Validation of ongoing environmental annoyance. Our selection of participants was based on the questions about environmentally related annoyance 3 years prior to our present study. As a validation of the present state, the subset of persons ( $\mathrm{N}=84$ ) participating in the cortisol/ logbook study responded to a modified version of the
Questionnaire on Chemical and General Environmental Sensitivity (23). This questionnaire is comprised of questions about reactions to various environmental, physical, and psychological stimuli and yielded clearly higher scores for the environmentally annoyed groups than for the referents on most of the subscales even though, as expected in a subclinical population-based study, only a minority of the annoyed persons fulfilled the criteria for having multiple chemical sensitivity (defined as reporting maximum annoyance for one or more of the eight questions about sensitivity to chemical smells, 18 persons) or environmental sensitivity (defined as reporting maximum annoyance in one or more of the eight questions concerning electrical sensitivity, 5 persons). These results confirm an increased subjective sensitivity to a variety of environmental stimuli among the electricity- and smell-annoyed participants at the time of our study. This state clearly distinguished them from the referents (table 2).

Analysis of the nonparticipants. The large survey from which the participants of our study were recruited has been shown to be fairly representative of the total Scanian population in Sweden with respect to age, gender, and health care utilization (21). The proportion of invited persons who finally participated in, and completed, our study was $27 \%$ (85 of 315 ) for the cases and $24 \%$ ( 56 of 235) for the referents. This result may give rise to concern about selection bias. Consequently, we compared the invited persons who did not participate,

Table 1. Characteristics of the participants. $(G H Q=$ general health questionnaire, $S R H=$ self-rated health $)$

\begin{tabular}{|c|c|c|c|c|c|c|c|}
\hline \multirow[t]{3}{*}{ Group } & \multicolumn{7}{|c|}{ Characteristic } \\
\hline & \multicolumn{2}{|c|}{ Age (years) } & \multirow{2}{*}{$\begin{array}{c}\text { Gender } \\
\text { (women) } \\
(\%)\end{array}$} & \multicolumn{2}{|c|}{$\mathrm{GHQ}^{\text {a }}$ score } & \multicolumn{2}{|c|}{$\mathrm{SRH}^{\mathrm{b}}$ score } \\
\hline & Mean & SD & & Mean & SD & Mean & SD \\
\hline Electrically annoyed $(\mathrm{N}=17)$ & 42.7 & 8.9 & 53 & 1.9 & 0.6 & 4.7 & 1.3 \\
\hline Smell-annoyed (N=29) & 43.4 & 9.6 & 59 & 1.8 & 0.4 & 4.7 & 1.2 \\
\hline Generally annoyed ( $\mathrm{N}=39)$ & 44.3 & 9.0 & 47 & 1.9 & 0.4 & 4.4 & 1.2 \\
\hline Referents $(\mathrm{N}=56)$ & 43.3 & 9.8 & 54 & 1.7 & 0.4 & 5.4 & 1.3 \\
\hline
\end{tabular}

a Scale $1-4$.

b Scale $1-7$.

Table 2. Mean annoyance scores in the modified questionnaire on chemical and general environmental sensitivity.

\begin{tabular}{|c|c|c|c|c|c|c|c|c|c|c|c|c|c|c|}
\hline \multirow[t]{3}{*}{ Group } & \multicolumn{14}{|c|}{ Symptom } \\
\hline & \multicolumn{2}{|c|}{$\begin{array}{c}\text { General } \\
\text { environmental } \\
\text { sensitivity } \\
\text { (I physical) }\end{array}$} & \multicolumn{2}{|c|}{$\begin{array}{c}\text { General } \\
\text { environmental } \\
\text { sensitivity } \\
\text { (II psychological) }\end{array}$} & \multicolumn{2}{|c|}{$\begin{array}{c}\text { Body } \\
\text { sensitivity } \\
\text { and } \\
\text { exhaustion }\end{array}$} & \multicolumn{2}{|c|}{$\begin{array}{l}\text { Respiratory } \\
\text { sensitivity }\end{array}$} & \multicolumn{2}{|c|}{$\begin{array}{l}\text { Nonspecific } \\
\text { multiple } \\
\text { chemical } \\
\text { sensitivity }\end{array}$} & \multicolumn{2}{|c|}{$\begin{array}{l}\text { Self-reported } \\
\text { multiple } \\
\text { chemical } \\
\text { sensitivity }\end{array}$} & \multicolumn{2}{|c|}{$\begin{array}{l}\text { Electrical } \\
\text { sensitivity }\end{array}$} \\
\hline & Mean & SD & Mean & SD & Mean & SD & Mean & SD & Mean & SD & Mean & SD & Mean & SD \\
\hline Electrically annoyed $(\mathrm{N}=17)$ & 24.3 & 15.0 & 16.3 & 10.9 & 7.5 & 5.9 & 4.9 & 6.7 & 10.0 & 7.6 & 10.3 & 9.2 & 1.9 & 3.0 \\
\hline Smell-annoyed (N=29) & 20.2 & 7.8 & 12.1 & 8.2 & 4.2 & 3.9 & 1.9 & 3.5 & 9.0 & 4.7 & 8.5 & 7.3 & 1.3 & 2.9 \\
\hline Generally annoyed ( $N=39)$ & 28.4 & 11.8 & 20.0 & 10.3 & 8.3 & 5.7 & 4.6 & 5.4 & 14.2 & 6.1 & 15.6 & 10.1 & 5.5 & 7.5 \\
\hline Referents $(\mathrm{N}=56)$ & 13.5 & 10.6 & 10.2 & 8.3 & 3.5 & 3.6 & 0.9 & 2.1 & 5.3 & 4.7 & 3.8 & 6.2 & 0.4 & 1.0 \\
\hline
\end{tabular}


with the participants. Among the referents, there were no significant differences between the participants and nonparticipants with respect to age or gender. Participants are often believed to be healthier than nonparticipants, and, therefore, we also compared the self-rated health status at the time of the initial large population study, performed 3 years prior to our present study. There were no significant differences between the participants and nonparticipants with respect to self-rated health [according to SRH-7 (24)] or mental well-being, assessed using the 12-item General Health Questionnaire (GHQ-12) (25). Among the environmentally annoyed persons, the proportion of men was significantly larger among the participants than among the nonparticipants (48\% versus 29\%); also, the participants were significantly older than the nonparticipants. However, there was no difference with respect to self-rated health or mental well-being at the time of the first survey. Moreover, there were no significant differences in the number or severity of environmental factors reported as annoying. More-detailed data and results of the testing of these differences can be obtained on request from the first author.

\section{Design}

Our present study was nested within a 2-week logbook monitoring of the participants' psychological adaptation to everyday life. The design was aimed at determining the participants' physiological functioning, as measured by salivary cortisol, by adopting a repeated-measures procedure in two parts in parallel with self-reports of stress and health complaints. In the first part, the participants were monitored during three ordinary weekdays and one weekend day in the following sequence: Wednesday, Sunday, Tuesday, and Thursday. On each of these days, the participants collected saliva at four prespecified time points: (i) awakening, (ii) 30 minutes after awakening, (iii) 8 hours after awakening, and (iv) at 9 o'clock in the evening. Logbook entries were made at three prespecified time points: (i) at awakening, (ii) 8 hours after awakening, and (iii) at 9 o'clock in the evening. In the second part, the participants were monitored during the day after being subjected to the suppression of the HPA axis by means of dexamethasone. The second part was initiated approximately 1 week after the first part. The participants were instructed to take a 0.5 -mg tablet of dexamethasone around 2300 on the evening before the day of the cortisol sampling, which was similarly paralleled by logbook entries, and conducted at the prespecified time points.

\section{Procedure}

Before the sampling period, the participants were carefully instructed and trained in how to make logbook en- tries and how to sample salivary cortisol. Accordingly, the participants were told to make logbook entries three times a day and collect saliva samples by placing the swab from the sampling tube in the mouth until hydrated, but no longer than 5 minutes. To secure the participants' correct understanding, we gave each person written information together with their logbook and four kits of saliva sampling tubes (Salivette ${ }^{\circledR}$, Sarstedt Ltd, Leicester, UK). To ensure a high quality of saliva samples, we instructed the participants to refrain from brushing their teeth after awakening until they had obtained the second saliva sample. This request was primarily to avoid swabs being contaminated by microbleeding from the gum. The participants were also instructed to refrain from smoking and eating heavy meals 1 hour prior to the saliva sampling. To facilitate the collection of the saliva tubes, each participant received prestamped envelopes to be returned after each day of sampling. In case of hindrance, the participants were instructed to store the samples in the refrigerator (at home or at work) until they were able to mail them. On arrival at the clinic, the samples were immediately frozen until their analysis.

\section{Ethics}

All of the participants gave their written informed consent to participate. The study protocol was approved by the Ethics Committee of Lund University (LU 343-00; LU 147-01).

\section{Measurement of cortisol in saliva}

The assay used for determining cortisol in saliva was a competitive radioimmunoassay, the Spectria Cortisol Coated Tube RIA, purchased from Orion Diagnostica, Espoo, Finland. The assay was designed for quantitative in vitro measurement of cortisol in serum, plasma, urine, and saliva. The analysis was carried out according to the manufacturer's specifications. The sample volume was $150 \mathrm{ml}$, the range of the standard solutions prepared was $1.0-100.0 \mathrm{nmol} / 1$, and the incubation time was 30 minutes at $37^{\circ} \mathrm{C}$. The sensitivity was given by the manufacturer as twice the standard deviation (SD) of the zero binding value in saliva, namely, $0.8 \mathrm{nmol} / \mathrm{l}$; the bias was given as $110 \%(103-115 \%)$, the intraassay variation as $5.4 \%$, and the interassay variation as $7.3 \%$. The cross-reactivity of the antiserum used was tested by the manufacturer to be $5 \alpha$-dihydrocortisol $(84.3 \%), 21$ desoxycortisol (78.8\%), prednisolone (45.3\%), 53-dihydrocortisol (11.9\%), and 6 $\alpha$-methylprednisolone $(11.0 \%)$. These components are not relevant for healthy persons. The cross-reactivity to cortisone was $<0.2 \%$. A 1470 Wizard gamma counter (Wallac, Turku, Finland) was used for measuring radioactivity. A method evaluation of certified reference material in water 
performed by our laboratory showed no bias of the method, the recovery being $97 \%$ (95\% confidence interval $94 \%-100.9 \%$ ). The limit of detection was 1.59 $\mathrm{nmol} / \mathrm{l}$. The between-run coefficients of variation $(\mathrm{CV})$ were $19 \%$ at $11.5 \mathrm{nmol} / 1$ and $16 \%$ at $49.2 \mathrm{nmol} / \mathrm{l}(26)$.

To show equivalence between different runs, natural saliva samples at the two mentioned concentrations ( $11.5 \mathrm{nmol} / \mathrm{l}$ and $49.2 \mathrm{nmol} / \mathrm{l})$ were used as control materials and analyzed together with the samples. Westgard control charts were used to document that the analytical method remained under analytical and statistical control-in other words, that the trueness and the precision of the analytical methods remained stable. The performance of the methods has also been validated by participation in interlaboratory comparison schemes (26-28).

\section{Measures}

Questionnaires. All of the participants filled out a comprehensive sample of questionnaires, parts of which were used in our present study to characterize the groups. The parts that were used to describe the participants were mental well-being [GHQ-12 (25)], self-rated health [SRH-7 (24)], and the CGES questionnaire (23) (an extensive questionnaire on chemical and general environmental sensitivity; results are more closely described under "Validation of Ongoing Environmental Annoyance"). The characteristics of the participants with respect to these variables are shown in tables 1 and 2. [See also Österberg et al (22).]

Cortisol. The variables analyzed in our study were (i) the cortisol concentration (nmol/l) at the four time points, (ii) the relative awakening response (defined as the percentage increase between the first and second samples), (iii) the maximum morning concentration (nmol/l), and (iv) the decline over the day (defined as the $\mathrm{nmol} / \mathrm{l}$ difference between the maximum morning concentration and the sample at 2100 in the evening).

Logbook. The logbook contained the 12-item stress and energy inventory (29), which measures feelings of arousal in two dimensions, stress (eg, tense, stressed) and energy (eg, energetic, active) (6 items per dimension). This inventory has specifically been designed to be used with working populations, and its usability has previously been shown in different occupational groups (30). The ability to monitor patterns of feelings of arousal within and across days has also been demonstrated (31).

The stress dimension covers a range from negatively valued, high-activity states to positively valued, lowactivity states and was recorded three times on each day of the saliva sampling. The internal consistency, as measured by Cronbach's alpha, varied from 0.86 to 0.91 over the different days and time points. The energy dimension covers the range of positively valued, high-activity states to negatively valued, low-activity states. Items were responded to on a six-point scale (range 05 ), with verbal anchors reflecting the intensity with which the respondent experienced the specific state (eg, being relaxed, tense, stressed, etc). Cronbach's alpha varied from 0.80 to 0.88 . For both dimensions, higher scores indicated more experience of stress or energy. The stress and energy scores were calculated as the mean score of the items comprising each dimension. The Pearson correlation between the stress and energy scores ranged from 0.18 to 0.36 over the different days and time points.

The logbook also contained the 13-item Lund Subjective Health Complaints (SHC-13) questionnaire, an inventory assessing the intensity of 13 common health complaints experienced during the day, including symptoms often reported by persons suffering from environmental illness, such as headache, dizziness, forgetfulness, nausea, rash, heat sensation or sweating, "flu-like" symptoms, back pain, neck-shoulder pain, stomach pain, flatulence, nervousness, and palpitations. This particular set of items has been developed by the Department of Occupational and Environmental Medicine at the Lund University Hospital. The items were responded to on a five-point scale indicating the degree of having experienced a specific symptom during the day that has just passed, from 1 "not at all" to 5 "very much". In our present study, a global measure, representing the mean score of all items, was used. Cronbach's alpha varied from 0.74 to 0.83 over the days. The SHC-13 questionnaire was completed once a day, in the evening.

Missing data. Although there were no dropouts from the study, there were some observations of occasional missing data. Altogether about $5 \%$ of the cortisol samples were missing or dry (133 of 2820). The proportion of missing cortisol values was twice as high at awakening $(8.2 \%)$ than at the other three time points $(3.4 \%$ to $4.1 \%)$.

As regards self-reports, 3.3\% (70/2115) of the stress ratings and $3.5 \%$ (73/2115) of the energy ratings were missing. There were about three times as many missing stress and energy ratings at the assessment 8-hours after awakening $(5.8 \%$ and $5.7 \%)$ than at awakening (2.4\% and $2.3 \%)$ and at 9 o'clock in the evening (1.7\% and $2.4 \%)$. As regards the subjective health complaints that were assessed once daily at 9 o'clock in the evening, $1.6 \%$ of the values were missing. The generally low proportion of missing values and the lack of a clear pattern in the missing data across groups suggests that the influence of any potential bias source is negligible. In addition, the selected statistical procedures are well suited to reduce the impact of missing values (32). 


\section{Data management}

Due to the positively skewed distributions and the heteroscedastic variances (proportional to the level of measurements) of the biomarker data, all of the concentrations of the biomarkers were transformed to be statistically analyzed on logarithmic scales. To lessen the impact of extreme outliers ( $>3 \mathrm{SD}$ ), the relative awakening response scores and decline over the day, which included negative numbers, were ranked before being subjected to statistical analysis (data from the dexamethasone suppression day were ranked and analyzed independently). For descriptive purposes, crude medians, as well as the 10th and 90th percentiles, are reported for cortisol measures, whereas the crude means and standard deviations are presented for the self-report data.

\section{Statistical analysis}

The general linear MIXED models module in SPSS 11.5 was used to specify a repeated measures model (SPSS Inc, Chicago, IL, USA). The models were solved using the restricted maximum likelihood (REML) method. The categorical predictors were group (with four groups, EA, SA, GA, and REF), day (four levels), and time of day (four levels for cortisol, three levels for self-reported stress). The other dependent variables were measured only once per day, and, hence, time of day was not included in the analyses. Awakening time (ie, time of the first sample), age, and gender were introduced as covariates in the model. The dependent variables were absolute cortisol concentrations at four time points over the day, cortisol awakening response, maximum morning concentration, cortisol decline over the day, and selfreported stress and energy. The statistical modeling also included the two-way interactions group by day and group by time of day (the latter only for the absolute cortisol concentrations and self-reported stress and energy), to find possible differential patterns of reactions between the groups. For all of the analyses, a series of first-order autoregressive covariance structures was tested, as well as a compound symmetry covariance structure. The Schwarz Bayesian Information Criterion was used to guide the final selection of the covariance structure. Because the repeated measurements across days and the diurnal cortisol variation within days made it somewhat difficult to select between a compound symmetry or first-order autoregressive co-variance structure indisputably, supplementary analyses were performed in which each day was analyzed separately. In these analyses, a first-order autoregressive co-variance structure was used, as this structure described the pattern of correlation within days slightly better, but it performed slightly worse when all the days were included.

The selection of covariate factors and interactions to be included in the final model was based on a back- wards stepwise deletion model, with the factors "group", "day", and "time of day" as forced-in variables. Initial$1 y$, all of the factor terms were entered simultaneously into the model, including the two-way interactions group by day and group by time of day, as well as the covariates awakening time, age, and gender. The limit of the significance of covariates to be included in the model was set at 0.20 , that is, variables or interactions not reaching a $\mathrm{P}$-value below 0.20 were eliminated from the model in the next step. This higher limit prevented much of the bias that otherwise may have arisen from this selection method (33-35).

If statistical significance was reached in the final model, post hoc testing was performed. P-values of $\leq 0.05$ were considered statistically significant. Statistically significant results from the estimated models are expressed as the post hoc difference between the mean scores, and the $95 \%$ confidence intervals (95\% CI). To facilitate the level comparisons between the physiological and psychological measures, statistically significant group differences are also shown in standard deviation units (Z-scores).

A possible association between self-reported stress or energy scores and cortisol was examined by introducing the stress or energy score separately as a covariate in the model. Each time point was separately analyzed. In the morning, correlations were examined between stress and energy scores and (i) the first morning sample, (ii) the relative awakening response, and (iii) a mean value of the two morning samples. The interactions group by stress and group by energy were introduced to examine possible differences in the association between the groups at the different time points.

Likewise, the possible association between cortisol and subjective health complaints was examined by introducing the SHC-13 score as a covariate in the model. Only the 2100 hour sample was included, since the SHC questionnaire was responded to in the evening only. The interaction group by SHC-13 score was introduced to examine possible differences in the association with cortisol between the groups. The dexamethasone suppression day was not included in these analyses.

The day of the dexamethasone suppression test was analyzed separately; the cortisol concentration and the stress or energy scores were analyzed using the aforementioned statistical procedure (ie, excluding the predictor day), while the cortisol awakening response, maximum morning concentration, decline over the day, and SHC-13 scores were analyzed using the univariate analysis of variance (ANOVA) procedure in SPSS (SPSS Inc, Chicago IL, USA). To examine the cortisol suppression in relation to the "normal" days, all 5 days were introduced simultaneously, and the day effect was tested. 


\section{Results}

\section{Cortisol}

On ordinary days (ie, the days without dexamethasone suppression), there were no statistically significant differences between the groups with regard to the cortisol concentrations $(\mathrm{P}=0.16)$, maximum morning concentration $(\mathrm{P}=0.60)$, relative awakening response $(\mathrm{P}=0.62)$, or decline during the day $(\mathrm{P}=0.73)$ (for descriptive data, see tables 3 and 4). There were no significant interaction effects between group and time of day or group and day, indicating that all of the groups showed a similar pattern within and between days. All of the groups had lower overall cortisol concentrations on Sunday than on the other days, but this difference disappeared when awakening time was controlled for $(\mathrm{P}=0.16)$. The median relative awakening responses on the weekdays were between $12 \%$ and $74 \%$ across the groups, and a little lower on Sunday (median between 2\% and 18\%) (for descriptive data, see table 4).

For all of the groups, the awakening response was significantly lower on Sunday than on the weekdays, and this difference remained even when awakening time was adjusted for $(\mathrm{P}<0.002)$, with no interaction between group and day, indicating a similar pattern between days for all of the groups. The maximum morning concentration was also significantly lower on Sunday than on Wednesday and Thursday $(\mathrm{P}<0.026)$, but not lower than the Tuesday values, again with no interaction between group and day. The median maximum morning concentration was between $16.8 \mathrm{nmol} / \mathrm{l}$ and $27.0 \mathrm{nmol} / \mathrm{l}$ for all of the groups. All of the groups showed similar median declines over the day, from $23.3 \mathrm{nmol} / 1$ to $12.7 \mathrm{nmol} / 1$. [See table 4 for descriptive data on the relative awakening response, maximum morning concentration, and decline over the day.] The evening concentrations were between $2.6 \mathrm{nmol} / \mathrm{l}$ and $4.1 \mathrm{nmol} / \mathrm{l}$. A graphic presentation of the median cortisol concentration at the given time points on different days for each group is given in figures 1-5.

However, when the days were analyzed separately, there was a significant difference on the first day of sampling, weekday 1 (Wednesday). On this day, the GA group had a higher overall mean cortisol concentration than the referents $(2.0 \mathrm{nmol} / \mathrm{l}, 95 \% \mathrm{CI} 1.6-2.5 \mathrm{nmol} / \mathrm{l}$, $\mathrm{P}=0.020)$ and the SA group $(2.5 \mathrm{nmol} / \mathrm{l}, 95 \% \mathrm{CI} 1.7-3.5$

Table 3. Medians and the 10th and 90th percentiles for the cortisol concentrations ( $\mathrm{nmol} / \mathrm{l})$ during ordinary weekdays, Sunday and the day after the dexamethasone suppression. $(10$ th $=10$ th percentile, 90th $=90$ th percentile $)$

\begin{tabular}{|c|c|c|c|c|c|c|c|c|c|c|c|c|}
\hline \multirow[t]{3}{*}{ Weekday } & \multicolumn{12}{|c|}{ Time point } \\
\hline & \multicolumn{3}{|c|}{ Awakening } & \multicolumn{3}{|c|}{30 minutes after awakening } & \multicolumn{3}{|c|}{8 hours after awakening } & \multicolumn{3}{|c|}{9 o'clock in the evening } \\
\hline & Median & 10th & 90th & Median & 10th & 90th & Median & 10th & 90th & Median & 10th & 90th \\
\hline \multicolumn{13}{|l|}{ Wednesday } \\
\hline Electrically annoyed group a & 16.2 & 13.0 & 32.2 & 23.7 & 13.7 & 38.1 & 7.4 & 5.4 & 11.5 & 4.1 & 2.2 & 7.8 \\
\hline Smell-annoyed group ${ }^{\mathrm{b}}$ & 14.8 & 8.0 & 21.7 & 20.2 & 11.2 & 30.4 & 7.4 & 4.1 & 11.2 & 2.7 & 1.4 & 8.6 \\
\hline Generally annoyed group c & 16.5 & 10.9 & 31.1 & 22.7 & 13.9 & 41.4 & 9.1 & 4.3 & 16.3 & 3.5 & 1.5 & 7.2 \\
\hline Referents $^{d}$ & 12.7 & 6.0 & 26.9 & 23.5 & 10.7 & 54.9 & 6.6 & 3.9 & 12.6 & 3.1 & 1.3 & 9.0 \\
\hline \multicolumn{13}{|l|}{ Tuesday } \\
\hline Electrically annoyed group ${ }^{a}$ & 17.5 & 7.2 & 23.7 & 25.9 & 16.8 & 39.4 & 7.0 & 3.2 & 15.5 & 2.8 & 1.7 & 6.5 \\
\hline Smell-annoyed group ${ }^{\mathrm{b}}$ & 16.3 & 7.9 & 33.0 & 20.6 & 11.0 & 32.8 & 6.3 & 3.7 & 13.9 & 2.7 & 0.9 & 9.1 \\
\hline Generally annoyed group c & 15.0 & 8.5 & 28.1 & 21.2 & 14.3 & 34.2 & 6.8 & 4.3 & 13.1 & 3.5 & 1.8 & 9.1 \\
\hline Referents $^{d}$ & 12.8 & 8.7 & 29.8 & 19.4 & 10.8 & 38.4 & 6.1 & 3.8 & 13.5 & 2.9 & 1.2 & 8.0 \\
\hline \multicolumn{13}{|l|}{ Thursday } \\
\hline Electrically annoyed group a & 14.3 & 11.0 & 19.5 & 26.6 & 10.4 & 40.3 & 7.9 & 3.9 & 13.6 & 3.9 & 2.6 & 7.4 \\
\hline Smell-annoyed group ${ }^{\mathrm{b}}$ & 17.0 & 10.0 & 33.0 & 22.4 & 12.4 & 39.0 & 5.7 & 3.4 & 10.0 & 2.9 & 1.5 & 5.5 \\
\hline Generally annoyed group c & 15.9 & 9.8 & 31.1 & 21.7 & 10.2 & 56.0 & 6.5 & 3.0 & 18.0 & 4.0 & 1.8 & 13.2 \\
\hline Referents $^{d}$ & 16.8 & 8.2 & 29.7 & 23.3 & 12.6 & 40.0 & 7.1 & 3.4 & 14.7 & 3.3 & 1.4 & 10.5 \\
\hline \multicolumn{13}{|l|}{ Sunday } \\
\hline Electrically annoyed group a & 15.1 & 12.2 & 19.7 & 18.2 & 7.5 & 29.4 & 6.6 & 3.8 & 13.9 & 3.0 & 1.3 & 7.0 \\
\hline Smell-annoyed group ${ }^{\mathrm{b}}$ & 12.1 & 7.2 & 25.9 & 15.2 & 7.4 & 33.1 & 6.4 & 3.7 & 14.2 & 3.3 & 1.8 & 8.0 \\
\hline Generally annoyed group c & 16.2 & 9.5 & 25.0 & 17.5 & 9.8 & 29.4 & 6.6 & 3.7 & 10.1 & 3.3 & 1.4 & 8.6 \\
\hline Referents $^{d}$ & 14.5 & 9.4 & 26.5 & 17.3 & 10.6 & 25.5 & 5.8 & 2.8 & 14.3 & 2.6 & 1.0 & 13.3 \\
\hline \multicolumn{13}{|l|}{ Dexamethasone Suppression } \\
\hline Electrically annoyed group a & 2.8 & 0.3 & 4.9 & 2.7 & 0.9 & 4.9 & 2.7 & 1.1 & 11.6 & 2.3 & 0.9 & 10.4 \\
\hline Smell-annoyed group ${ }^{\mathrm{b}}$ & 2.6 & 0.8 & 5.8 & 2.3 & 0.8 & 10.3 & 3.2 & 0.8 & 5.5 & 2.0 & 1.0 & 5.2 \\
\hline Generally annoyed group c & 2.5 & 0.9 & 15.0 & 2.4 & 1.0 & 12.4 & 2.7 & 1.2 & 10.4 & 2.2 & 0.9 & 14.7 \\
\hline Referents $^{d}$ & 2.0 & 0.6 & 6.0 & 2.4 & 0.5 & 9.2 & 2.3 & 0.3 & 9.9 & 2.3 & 0.5 & 7.3 \\
\hline
\end{tabular}


Table 4. Median and the 10th and 90th percentile relative cortisol awakening response, maximum cortisol morning concentration, and cortisol decline over the day. (10th = 10th percentile, 90the $=90$ th percentile)

\begin{tabular}{|c|c|c|c|c|c|c|c|c|c|}
\hline \multirow[t]{2}{*}{ Weekday } & \multicolumn{3}{|c|}{$\begin{array}{l}\text { Relative awakening } \\
\text { response (\%) }\end{array}$} & \multicolumn{3}{|c|}{$\begin{array}{l}\text { Maximum morning } \\
\text { concentration }(\mathrm{nmol} / \mathrm{l})\end{array}$} & \multicolumn{3}{|c|}{$\begin{array}{l}\text { Decline over } \\
\text { the day }(\mathrm{nmol} / \mathrm{l})\end{array}$} \\
\hline & Median & 10th & 90th & Median & 10th & 90th & Median & 10th & 90th \\
\hline \multicolumn{10}{|l|}{ Wednesday } \\
\hline $\begin{array}{l}\text { Electrically annoyed group a } \\
\text { Smell-annoyed group }{ }^{\mathrm{b}} \\
\text { Generally annoyed group }{ }^{\mathrm{a}} \\
\text { Referents }^{\mathrm{d}}\end{array}$ & $\begin{array}{l}37.6 \\
43.4 \\
31.8 \\
73.1\end{array}$ & $\begin{array}{l}-14.7 \\
-26.0 \\
-16.3 \\
-17.2\end{array}$ & $\begin{array}{l}154.9 \\
249.4 \\
158.5 \\
247.2\end{array}$ & $\begin{array}{l}23.8 \\
21.7 \\
25.1 \\
25.1\end{array}$ & $\begin{array}{l}16.0 \\
12.5 \\
15.3 \\
10.7\end{array}$ & $\begin{array}{l}38.1 \\
30.4 \\
41.4 \\
54.9\end{array}$ & $\begin{array}{l}-19.6 \\
-19.0 \\
-20.5 \\
-20.0\end{array}$ & $\begin{array}{l}-35.1 \\
-28.4 \\
-37.4 \\
-40.3\end{array}$ & $\begin{array}{r}-11.8 \\
-8.2 \\
-10.3 \\
-6.8\end{array}$ \\
\hline \multicolumn{10}{|l|}{ Tuesday } \\
\hline $\begin{array}{l}\text { Electrically annoyed group }{ }^{a} \\
\text { Smell-annoyed group }{ }^{b} \\
\text { Generally annoyed group }{ }^{c} \\
\text { Referents }^{d}\end{array}$ & $\begin{array}{l}71.3 \\
11.5 \\
40.0 \\
46.6\end{array}$ & $\begin{array}{r}-0.5 \\
-38.3 \\
-31.6 \\
-29.0\end{array}$ & $\begin{array}{l}134.8 \\
195.9 \\
200.0 \\
194.5\end{array}$ & $\begin{array}{l}26.3 \\
22.0 \\
22.7 \\
20.7\end{array}$ & $\begin{array}{l}19.6 \\
14.5 \\
14.4 \\
12.0\end{array}$ & $\begin{array}{l}39.4 \\
36.3 \\
34.2 \\
39.8\end{array}$ & $\begin{array}{l}-22.7 \\
-20.9 \\
-18.8 \\
-17.1\end{array}$ & $\begin{array}{l}-36.6 \\
-32.7 \\
-28.3 \\
-33.2\end{array}$ & $\begin{array}{r}-16.8 \\
-7.1 \\
-6.2 \\
-6.7\end{array}$ \\
\hline \multicolumn{10}{|l|}{ Thursday } \\
\hline $\begin{array}{l}\text { Electrically annoyed group }{ }^{a} \\
\text { Smell-annoyed group }{ }^{b} \\
\text { Generally annoyed group }{ }^{c} \\
\text { Referents }^{d}\end{array}$ & $\begin{array}{l}73.7 \\
32.7 \\
63.5 \\
36.7\end{array}$ & $\begin{array}{r}19.4 \\
-52.4 \\
-38.2 \\
-29.4\end{array}$ & $\begin{array}{l}193.7 \\
190.0 \\
138.5 \\
178.0\end{array}$ & $\begin{array}{l}26.6 \\
27.0 \\
23.5 \\
23.4\end{array}$ & $\begin{array}{l}10.4 \\
13.6 \\
15.4 \\
13.7\end{array}$ & $\begin{array}{l}40.3 \\
46.4 \\
56.0 \\
40.0\end{array}$ & $\begin{array}{l}-21.3 \\
-23.3 \\
-17.7 \\
-19.2\end{array}$ & $\begin{array}{l}-36.8 \\
-42.4 \\
-37.1 \\
-38.1\end{array}$ & $\begin{array}{r}-6.8 \\
-12.1 \\
-5.7 \\
-9.4\end{array}$ \\
\hline \multicolumn{10}{|l|}{ Sunday } \\
\hline $\begin{array}{l}\text { Electrically annoyed group }{ }^{a} \\
\text { Smell-annoyed group }{ }^{b} \\
\text { Generally annoyed group }{ }^{c} \\
\text { Referents }^{d}\end{array}$ & $\begin{array}{r}2.8 \\
17.6 \\
16.3 \\
1.6\end{array}$ & $\begin{array}{l}-52.1 \\
-41.3 \\
-48.8 \\
-39.8\end{array}$ & $\begin{array}{r}76.8 \\
129.9 \\
82.0 \\
122.9\end{array}$ & $\begin{array}{l}18.8 \\
16.8 \\
20.0 \\
20.2\end{array}$ & $\begin{array}{l}13.6 \\
10.1 \\
12.9 \\
12.5\end{array}$ & $\begin{array}{l}29.4 \\
36.2 \\
29.7 \\
31.7\end{array}$ & $\begin{array}{l}-14.6 \\
-12.7 \\
-16.1 \\
-16.1\end{array}$ & $\begin{array}{l}-25.1 \\
-34.3 \\
-26.9 \\
-26.9\end{array}$ & $\begin{array}{r}-7.3 \\
-6.8 \\
-8.5 \\
-10.2\end{array}$ \\
\hline \multicolumn{10}{|l|}{ Dexamethasone suppression } \\
\hline $\begin{array}{l}\text { Electrically annoyed group a } \\
\text { Smell-annoyed group }{ }^{\mathrm{b}} \\
\text { Generally annoyed group c } \\
\text { Referents }^{\mathrm{d}}\end{array}$ & $\begin{array}{r}0.0 \\
0.0 \\
-8.3 \\
25.0\end{array}$ & $\begin{array}{l}-49.0 \\
-66.7 \\
-58.8 \\
-71.4\end{array}$ & $\begin{array}{r}53.3 \\
194.3 \\
466.7 \\
381.5\end{array}$ & $\begin{array}{l}2.7 \\
3.2 \\
3.8 \\
2.8\end{array}$ & $\begin{array}{l}1.5 \\
1.2 \\
1.5 \\
1.1\end{array}$ & $\begin{array}{r}4.9 \\
12.3 \\
15.0 \\
13.0\end{array}$ & $\begin{array}{r}0.3 \\
-0.9 \\
-1.0 \\
-0.3\end{array}$ & $\begin{array}{r}-2.9 \\
-9.9 \\
-10.8 \\
-4.9\end{array}$ & $\begin{array}{r}5.8 \\
2.5 \\
10.6 \\
3.9\end{array}$ \\
\hline
\end{tabular}

a $\mathrm{N}=17$.

b $\mathrm{N}=29$.

c $\mathrm{N}=39$.

d $\mathrm{N}=56$.

nmol/l, $\mathrm{P}=0.013)$. Expressed in standard deviation units, the differences between the mean scores were $0.2(95 \%$ CI 0.0-0.4) and 0.3 (95\% CI 0.1-0.5) Z-scores, respectively. There was no interaction effect between group and time of day, indicating a similar pattern over the day for all of the groups.

Dexamethasone suppression test. In the dexamethasone suppression test, the activity of the HPA axis was inhibited in all of the groups, with significantly lower cortisol concentrations the following morning than in the mornings without dexamethasone suppression $(\mathrm{P}<0.001)$ (table 3$)$. There were no significant differences in the cortisol concentration between the groups over the day, and no interaction between group and time, indicating a similar pattern over the day for all of the groups. All of the groups showed a similar awakening response, maximum morning concentration, and decline over the day. Figure 5 presents the median cortisol concentrations on the dexamethasone suppression day.

\section{Self-reported stress and energy}

During the days of the saliva sampling, the GA group scored higher on self-reported stress than both the ref- erents $(0.46,95 \%$ CI $0.23-0.70, \mathrm{P}<0.001)$ and the SA group $(0.44,95 \%$ CI $0.17-0.70, \mathrm{P}=0.002)$. Expressed in standard deviation units, these differences between the mean scores were 0.5 (95\% CI 0.3-0.8) and $0.5(95 \%$ CI 0.2-0.8) Z-scores, respectively. All of the groups reported the highest stress scores in the middle of the day (ie, 8 hours after awakening) and the lowest in the evening $(\mathrm{P}<0.001)$. All of the groups had lower stress scores on Sunday than on the weekdays $(\mathrm{P}<0.001)$. There was no interaction between group and day or time of day, indicating a similar pattern over days and time points for all of the groups (table 5). There were no significant differences between the groups with respect to the self-reported level of energy. All of the groups reported higher energy in the middle of the day than in the morning and evening $(\mathrm{P}<0.001)$ and lower energy on Sunday than on the other days $(\mathrm{P}<0.001)$.

\section{Association between cortisol and self-reported stress, energy and subjective health complaints}

There was no significant association between the selfreported stress or energy scores and the cortisol concentration at any of the examined time points. There was 


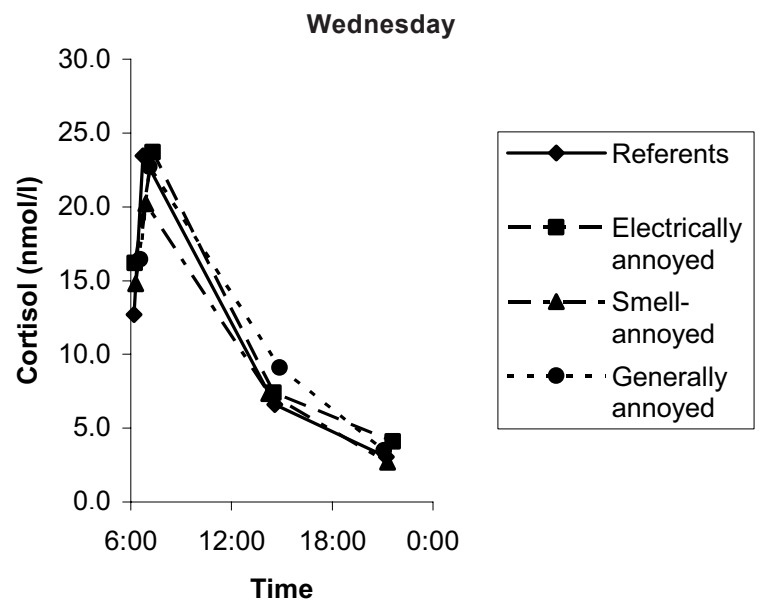

Figure 1. Median cortisol concentration at four time points on weekday 1.

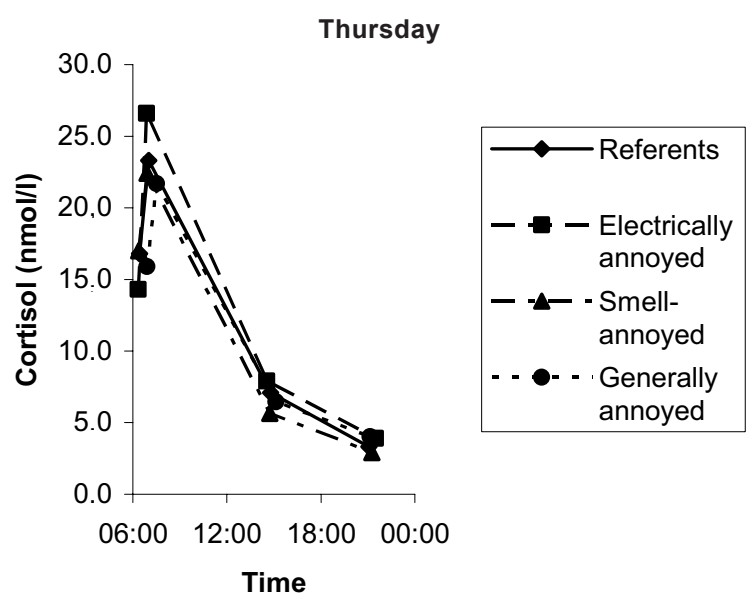

Figure 3. Median cortisol concentration at four time points on weekday 3.

no interaction effect between group and the stress or energy score. Nor was there a significant association between cortisol and the SHC-13 score. There was no interaction between group and the SHC-13 score.

\section{Discussion}

Despite higher levels of self-reported stress in the GA group, none of the environmentally annoyed groups showed more signs of a dysregulated HPA axis than the referents. The similar cortisol concentrations and stable diurnal pattern across and within days agrees fairly well with the results from previous studies with normal participants and does not support the hypothesis of subnormal physiological stress functioning in the environmentally annoyed groups (27). This view was also corroborated by the fact that all of the groups showed a significant suppression of the HPA axis on the day after the ingestion of dexamethasone.

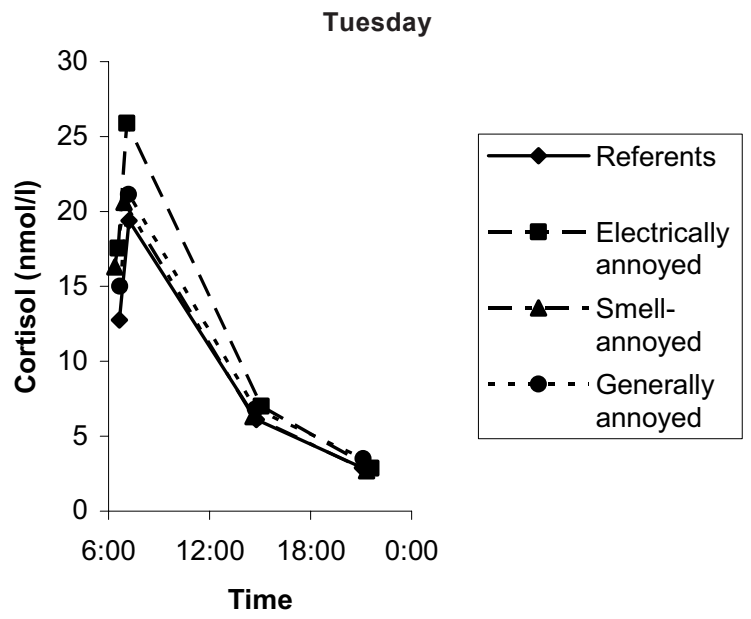

Figure 2. Median cortisol concentration at four time points on weekday 2.

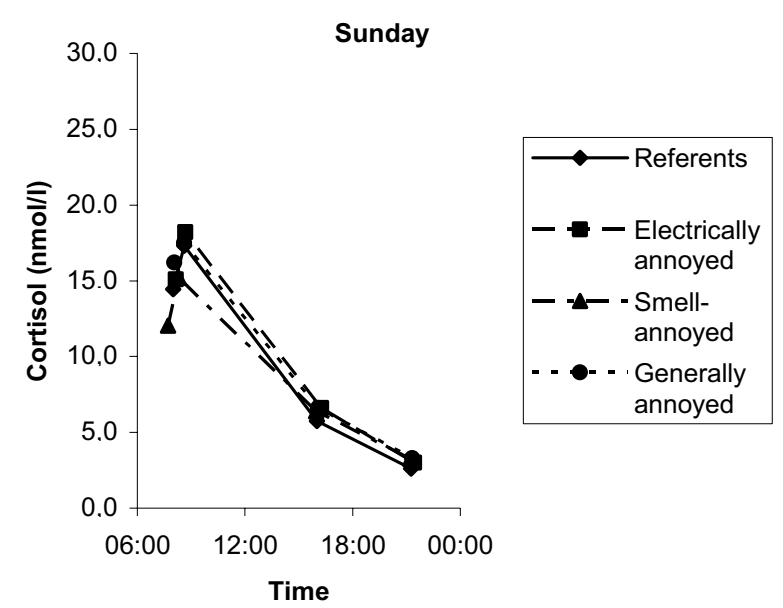

Figure 4. Median cortisol concentration on Sunday.

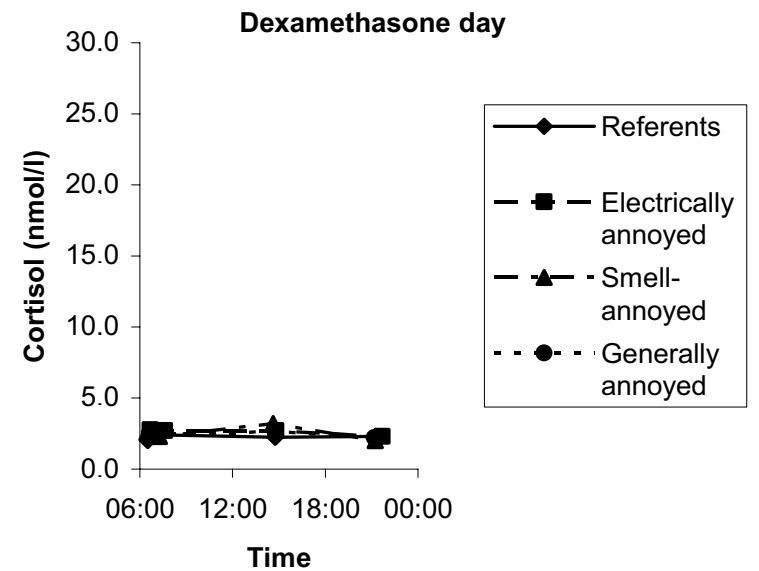

Figure 5. Median cortisol concentration on the dexamethasone suppression day.

However, the supplementary analyses of the separate days revealed that the GA group had slightly higher mean cortisol levels on the first day of the study, and that the EA group showed a tendency in the same di- 
Table 5. Subjective stress scores, measured by the Stress/Energy Inventory.

\begin{tabular}{|c|c|c|c|c|c|c|}
\hline \multirow[t]{3}{*}{ Weekday } & \multicolumn{6}{|c|}{ Time point } \\
\hline & \multicolumn{2}{|c|}{ Awakening } & \multicolumn{2}{|c|}{$\begin{array}{c}8 \text { hours after } \\
\text { awakening }\end{array}$} & \multicolumn{2}{|c|}{$\begin{array}{l}9 \text { o'clock in } \\
\text { the evening }\end{array}$} \\
\hline & Mean & SD & Mean & SD & Mean & SD \\
\hline \multicolumn{7}{|l|}{ Wednesday } \\
\hline Electrically annoyed group a & 2.5 & 0.8 & 3.0 & 1.0 & 3.0 & 1.0 \\
\hline Smell-annoyed group ${ }^{b}$ & 2.4 & 0.7 & 2.9 & 0.9 & 2.2 & 0.7 \\
\hline Generally annoyed group c & 3.0 & 0.9 & 3.2 & 1.1 & 2.9 & 0.9 \\
\hline Referents $^{d}$ & 2.4 & 0.8 & 2.9 & 0.9 & 2.3 & 0.7 \\
\hline \multicolumn{7}{|l|}{ Tuesday } \\
\hline Electrically annoyed group a & 2.9 & 0.9 & 3.6 & 1.1 & 2.3 & 0.6 \\
\hline Smell-annoyed group ${ }^{b}$ & 2.5 & 0.8 & 3.1 & 1.2 & 2.6 & 0.9 \\
\hline Generally annoyed group c & 3.1 & 1.0 & 3.3 & 1.0 & 2.8 & 0.9 \\
\hline Referents $^{d}$ & 2.5 & 0.8 & 3.2 & 0.9 & 2.4 & 0.9 \\
\hline \multicolumn{7}{|l|}{ Thursday } \\
\hline Electrically annoyed group a & 2.8 & 0.8 & 3.0 & 1.0 & 2.7 & 1.0 \\
\hline Smell-annoyed group ${ }^{b}$ & 2.4 & 0.8 & 3.4 & 1.1 & 2.4 & 0.8 \\
\hline Generally annoyed group c & 3.0 & 0.8 & 3.6 & 1.0 & 2.7 & 0.8 \\
\hline Referents ${ }^{d}$ & 2.4 & 0.8 & 2.9 & 0.9 & 2.3 & 0.7 \\
\hline \multicolumn{7}{|l|}{ Sunday } \\
\hline Electrically annoyed group a & 2.2 & 0.8 & 2.2 & 0.7 & 2.1 & 0.6 \\
\hline Smell-annoyed group ${ }^{b}$ & 2.0 & 0.6 & 2.3 & 0.8 & 2.0 & 0.6 \\
\hline Generally annoyed group c & 2.5 & 0.9 & 2.7 & 1.0 & 2.4 & 0.7 \\
\hline Referents ${ }^{d}$ & 2.2 & 0.6 & 2.4 & 0.7 & 2.1 & 0.7 \\
\hline \multicolumn{7}{|c|}{ Dexamethasone suppression } \\
\hline Electrically annoyed group a & 2.4 & 0.8 & 3.3 & 0.9 & 2.4 & 0.7 \\
\hline Smell-annoyed group ${ }^{b}$ & 2.6 & 0.9 & 3.1 & 0.8 & 2.2 & 0.6 \\
\hline Generally annoyed group c & 3.1 & 1.0 & 3.4 & 0.9 & 2.7 & 0.7 \\
\hline Referents $^{d}$ & 2.5 & 0.8 & 3.0 & 0.9 & 2.2 & 0.6 \\
\hline
\end{tabular}

rection, possibly indicating that these groups react more strongly to new situations. Interestingly, hyperreactivity to newness has been associated with increased sensitizability (36). In that the differences in the cortisol concentrations on the first day were numerically small (0.2 Z-score) and only observed after the statistical analysis procedure was optimized, one would not expect this finding to have any clinical bearing. On the other hand, it is possible that small differences in biological systems that do not attract the clinicians' immediate attention could, if given enough time, have a biologically significant effect. The fact that the EA group showed tendencies similar to those of the GA group in both self-reports and cortisol agrees fairly well with our results from previous experimental and epidemiologic studies on these groups $(1,22)$. It appears that a congruent pattern of differences is traceable across different contexts, the EA group appearing more similar to the GA group in ratings of distress and health complaints than to the SA group (1). Furthermore, it was observed that the GA group deviated more from the reference group with regard to both the CGES scales and the self-reports on the stress scores than the SA and EA groups. As mentioned, the GA group was also the only group that showed a statistically significantly higher cortisol level on the first day, although this difference was small. As regards selfreported stress, a similar pattern of differences was also observed during the 2-week monitoring, in which the present study in part was nested (unpublished observations). During this 2-week monitoring, we also observed that the GA group reported more subjective health symptoms and sleep disturbances, and they reported their daily life more negatively than the other groups did.

The selection of the participants was based on questions put to them approximately 3 years prior to our present study. However, as described in the methods section, in conjunction with our present study, the participants responded to the extensive CGES questionnaire regarding environmental sensitivity (23). The participants in the annoyance groups scored higher than the referents on all of the CGES scales, confirming the longstanding nature of environmental sensitivity. However, not all of the participants reported experiencing environmental annoyance or expectations of environmental annoyance reactions during the 2 -week study period. To test whether a simultaneous reporting of avoidance behaviors, expectations of hypersensitivity reactions, or the attribution of health complaints to electrical equipment and smells had an effect on the cortisol concentrations, supplementary analyses were performed using new groups, based on the self-reports made during the study period. However, this regrouping of the participants did not result in any additional observations of interest. No differences were found between the different attribution, avoidance, or expectancy groups with regard to the cortisol concentration, maximum morning concentrations, relative awakening response, or decline over the day.

Our findings in the present study, as well as other published (22) and unpublished findings or observations made by our research group, seem collectively to be consistent with the hypothesis that persons with a more widespread environmental annoyance show an increased tendency to report health complaints and experiences of stress. Because the groups were defined according to the degree to which they expressed annoyance in relation to electrical and chemical factors, one could perhaps argue that the labeling of the generally annoyed group (ie, GA group) is misleading. Combined annoyance or double annoyance would be a more accurate labeling. On the other hand, the ratings in the CGES questionnaire confirm that combined or double annoyance (ie, GA) is linked to annoyance related to several more environmental factors. Patients with other functional disorders, such as fibromyalgia, chronic low-back pain, and functional gastrointestinal disorders, have been found to 
perceive stressors as stronger and as more uncontrollable than controls perceive them (37). Observably the GA group's consistently high scores for stress and somatic complaints appear to fit this general picture well. These complaints could be due to either an increased tendency to pay attention to and worry about physiological signs and symptoms that are normally present in most people or a lower threshold for experiencing situations as threatening or intolerable, increasing the likelihood of stress reactions in everyday life (38). This pattern of "negative affectivity"(39) might explain why the GA group reported more subjective symptoms, stress, and complaints. However, such experiences of a higher psychological stress level obviously do not have to lead to a physiological stress response in the HPA axis, as measured by the secretion of cortisol.

With reference to the cognitive activation theory of stress (CATS) (40), one would expect cognitive experience of stress to lead to HPA-axis activation. Apart from the slightly higher cortisol levels in the GA group during the first sampling day, a general pattern of increased HPA activity was however not observed. One possible explanation for this finding could be that the stress and energy questionnaire does not contain the dimensions of stress that have previously seemed to trigger cortisol response, namely, uncertainty, novelty, lack of control, ego involvement, and helplessness $(41,42)$. Another possible interpretation is that the current levels of stress were not sufficient to induce increased HPA-axis activity. The present groups were occupationally active nonpatients with degrees of environmental annoyance that can best be described as slight to moderate, in contrast to the often severely disabling intolerance encountered in clinical cases, among whom physiological stress responses might be more readily observable. On the other hand, one cannot exclude an association between subjective stress and a physiological component, or effect, other than the one measured in our present study. For example, the HPA response is known to habituate to psychosocial stress more promptly than other stress systems, such as the sympathetic-adrenal-medulla (SAM) system (43).

However, a lack of correspondence between a selfreported and physiological stress response, measured as cortisol in saliva, has also been found in previous studies, as described in a review by Hjortskov et al (41). According to this review, the chances of finding possible associations between cortisol and self-reported stress should increase if day-profile measures of cortisol are used rather than one-point in time measures. Another suggestion was to compare levels on weekdays with levels on days of relaxation, such as weekends (41). However, following these guidelines did not result in any additional observations of associations between cortisol and self-reported stress scores in our data. This find- ing suggests that we are dealing with two different sources, or dimensions, of information on stress that need to be considered in order to gain a more complete view of the individual situation.

In conclusion, contrary to our expectations, the environmentally annoyed persons did not show any convincing signs of an increased activation of the HPA axis. However, being annoyed by both electrical devices and smells seemed to be related to increased psychological activation in terms of self-reported stress. Because the participants were otherwise healthy and recruited from the general population, the results imply that subtle psychological stress may be related to the development of environmental annoyance.

\section{Acknowledgments}

Anne Abildtrup, Dorrit Meincke, and Ulla Tegner are acknowledged for their skillful technical assistance. The authors would also like to thank the participants for their efforts to complete the study.

This study was supported by the Swedish Council for Work Life Research, grants 2001-0321 and 20010322, and the Vårdal Foundation, grant 2001-044.

\section{References}

1. Carlsson F, Karlson B, Orbaek P, Osterberg K, Ostergren PO. Prevalence of annoyance attributed to electrical equipment and smells in a Swedish population, and relationship with subjective health and daily functioning. Public Health. 2005;119(7):568-77.

2. Sparks PJ. Idiopathic environmental intolerances: overview. Occup Med. 2000;15(3):497-510.

3. Overmier JB. Sensitization, conditioning, and learning: can they help us understand somatization and disability? Scand J Psychol. 2002;43(2):105-12.

4. Winters W, Devriese S, Van Diest I, Nemery B, Veulemans $\mathrm{H}$, Eelen $\mathrm{P}$, et al. Media warnings about environmental pollution facilitate the acquisition of symptoms in response to chemical substances. Psychosom Med. 2003;65(3):332-8.

5. Siegel S, Kreutzer R. Pavlovian conditioning and multiple chemical sensitivity. Environ Health Perspect. 1997;105 Suppl 2:521-6.

6. Levine $\mathrm{S}$, Ursin H. What is stress? In: Brown MR, Rivier C, Koob G, editors. Stress: neurobiology and neuroendocrinology. New York: Marcel Decker; 1991. p. 3-21.

7. Brosschot JF. Cognitive-emotional sensitization and somatic health complaints. Scand J Psychol. 2002;43(2):113-21.

8. Edwards S, Clow A, Evans P, Hucklebridge F. Exploration of the awakening cortisol response in relation to diurnal cortisol secretory activity. Life Sci. 2001;68(18):2093-103.

9. Pruessner JC, Wolf OT, Hellhammer DH, Buske-Kirschbaum A, von Auer K, Jobst S, et al. Free cortisol levels after awakening: a reliable biological marker for the assessment of adren- 
ocortical activity. Life Sci. 1997;61(26):2539-49.

10. Kirschbaum C, Hellhammer DH. Salivary cortisol. In: Fink G, editor. Encyclopedia of Stress. San Diego (CA): Academic Press; 2000. p 379-83.

11. Wust S, Wolf J, Hellhammer DH, Federenko I, Schommer N, Kirschbaum C. The cortisol awakening response-normal values and confounds. Noise Health. 2000;2(7):79-88.

12. Biondi M, Picardi A. Psychological stress and neuroendocrine function in humans: the last two decades of research. Psychother Psychosom. 1999;68(3):114-50.

13. Heim C, Ehlert U, Hellhammer DH. The potential role of hypocortisolism in the pathophysiology of stress-related bodily disorders. Psychoneuroendocrinology. 2000;25(1):1-35.

14. Hubain PP, Staner L, Dramaix M, Kerkhofs M, Papadimitriou G, Mendlewicz J, et al. The dexamethasone suppression test and sleep electroencephalogram in nonbipolar major depressed inpatients: a multivariate analysis. Biol Psychiatry. 1998; 43(3):220-9.

15. Nicolson NA, van Diest R. Salivary cortisol patterns in vital exhaustion. J Psychosom Res. 2000;49(5):335-42.

16. Pruessner JC, Hellhammer DH, Kirschbaum C. Burnout, perceived stress, and cortisol responses to awakening. Psychosom Med. 1999;61(2):197-204.

17. Rief W, Shaw R, Fichter MM. Elevated levels of psychophysiological arousal and cortisol in patients with somatization syndrome. Psychosom Med. 1998;60(2):198-203.

18. Smyth J, Ockenfels MC, Porter L, Kirschbaum C, Hellhammer DH, Stone AA. Stressors and mood measured on a momentary basis are associated with salivary cortisol secretion. Psychoneuroendocrinology. 1998;23(4):353-70.

19. Gaab J, Huster D, Peisen R, Engert V, Heitz V, Schad T, et al. Hypothalamic-pituitary-adrenal axis reactivity in chronic fatigue syndrome and health under psychological, physiological, and pharmacological stimulation. Psychosom Med. 2002;64(6):951-62.

20. Gaab J, Huster D, Peisen R, Engert V, Schad T, Schurmeyer $\mathrm{TH}$, et al. Low-dose dexamethasone suppression test in chronic fatigue syndrome and health. Psychosom Med. 2002;64(2):311-8.

21. Carlsson F, Merlo J, Lindstrom M, Lithman T, Östergren P-O. Representativity of a Postal Public Health Questionnaire Survey in Sweden, with special reference to ethnic differences in participation. Scand J Public Health. In press.

22. Österberg K, Persson R, Karlson B, Ørbæk P. Annoyance and performance of three environmentally intolerant groups during experimental challenge with chemical odors. Scand J Work Environ Health. 2004;30(6):486-96.

23. Kiesswetter E, Sietmann B, Zupanic M, van Thriel C, Golka K, Seeber A. Verhaltenstoxikologische Aspekte der Prävalenz und Ätiologie "multipler chemischer Sensitivität" [Neurobehavioral aspects of the prevalence and etiology of "multiple chemical sensitivity"]. Allergologie. 1999;22:719-35.

24. Eriksson I, Unden AL, Elofsson S. Self-rated health: comparisons between three different measures: results from a population study. Int J Epidemiol. 2001;30(2):326-33.

25. Goldberg D, Williams P. A users' guide to the General Health Questionnaire. Windsor (UK): NFER-Nelson; 1988.

26. Garde AH, Hansen Å, Nikolajsen TB. An inter-laboratory comparison for determination of cortisol in saliva. Accredit Qual Assur. 2003;8(16):20.

27. Hansen ÅM, Garde AH, Christensen JM, Eller N, Netterstrøm B. Validation of a radio-immunoassay and establishment of a reference interval for salivary cortisol in healthy subjects in Denmark. Scand J Clin Lab Invest. 2003;63:1-9.

28. Westgard JO, Barry PL, Hunt MR, Groth T. A multi-rule Shewhart chart for quality control in clinical chemistry. Clin Chem. 1981;27(3):493-501.

29. Kjellberg A, Iwanowski S. Stress/Energi-formuläret: utveckling av en metod för skattning av sinnesstämning $\mathrm{i}$ arbetet [The stress/energy-questionnaire: development of a method for estimating work related mood]. Solna (Sweden): Arbetsmiljöinstitutet; 1989. Arbete och hälsa, No.: 1989:26.

30. Kjellberg A, Wadman C. Subjektiv stress och dess samband med psykosociala förhållanden och besvär. En prövning av Stress-Energi-modellen. [Subjective stress and its relation to psychosocial work conditions and health complaints. A test of the stress energy model.]. Stockholm: Arbetslivsinstitutet; 2002. Report No.: 2002:12.

31. Persson R, Garde AH, Hansen ÅM, Ørbæk P, Ohlsson K. The influence of production systems on self-reported arousal, sleepiness, physical exertion and fatigue-consequences of increasing mechanization. Stress Health. 2003;19(3):163-71.

32. Brown H, Prescott R. Applied mixed models in medicine. New York: Wiley; 1999.

33. Greenland S. Modeling and variable selection in epidemiologic analysis. Am J Public Health. 1989;79(3):340-9.

34. Maldonado G, Greenland S. Simulation study of confounderselection strategies. Am J Epidemiol. 1993;138(11):923-36.

35. Mickey RM, Greenland S. The impact of confounder selection criteria on effect estimation. Am J Epidemiol. 1989;129(1):125-37.

36. Bell IR, Schwartz GE, Peterson JM, Amend D. Symptom and personality profiles of young adults from a college student population with self-reported illness from foods and chemicals. J Am Coll Nutr. 1993;12(6):693-702.

37. Eriksen HR, Ursin H. Sensitization and subjective health complaints. Scand J Psychol. 2002;43(2):189-96.

38. Eriksen HR, Ursin H. Subjective health complaints, sensitization, and sustained cognitive activation (stress). J Psychosom Res. 2004;56(4):445-8.

39. Watson D, Pennebaker JW. Health complaints, stress, and distress: exploring the central role of negative affectivity. Psychol Rev. 1989;96(2):234-54.

40. Ursin H, Eriksen HR. The cognitive activation theory of stress. Psychoneuroendocrinology. 2004;29(5):567-92.

41. Hjortskov N, Garde AH, Ørbæk P, Hansen ÅM. Evaluation of salivary cortisol as a biomarker of self-reported mental stress in field studies. Stress Health. 2004;20:91-98.

42. Lundberg U. Methods and applications of stress research. Technol Health Care. 1995;3(1):3-9.

43. Schommer NC, Hellhammer DH, Kirschbaum C. Dissociation between reactivity of the hypothalamus-pituitary-adrenal axis and the sympathetic-adrenal-medullary system to repeated psychosocial stress. Psychosom Med. 2003;65(3):450-60.

Received for publication: 1 December 2004 